\title{
Model-driven decision support to facilitate efficient fresh food deliveries
}

\section{Modellgetriebene Entscheidungsunterstützung für die Zustellungen von frischen Lebensmitteln}

\author{
Christian Fikar
}

Institute for Production Management, Vienna University of Economics and Business, Welthandelsplatz 1, 1020 Vienna, Austria, christian.fikar@wu.ac.at

Received: 4 October 2019, received in revised form: 23 December 2019, accepted: 9 January 2020

\begin{abstract}
Summary
The delivery of fresh food is challenged by various uncertainties present in daily logistics operations. To facilitate successful operations, this work reviews the recent work on model-driven decision support systems to identify research gaps and derive implications. Introduced systems in literature mainly employ simulation or optimization methods and focus on the consideration of industry specifics such as short shelf lives and the importance of efficient temperature control. Therefore, food quality models are often integrated to enable one to monitor quality throughout supply chain operations and adjust planning procedure respectively. To strengthen research, future work focusing on a stronger consideration of customer-related factors and holistic approaches considering various interdependencies present in fresh food logistics operations are required.
\end{abstract}

Keywords: Food logistics, decision support, shelf life, simulation, optimization

\section{Zusammenfassung}

Die Zustellung von frischen Lebensmitteln ist komplex und geprägt von einer Vielzahl an logistischen Herausforderungen. Diese Arbeit zeigt Forschungsarbeiten der letzten Jahre in diesem Bereich auf, um nachhaltige und effiziente Lieferungen zu unterstützen. Der Fokus liegt auf entwickelten modellgetriebenen Entscheidungsunterstützungssystemen, der Ableitung von Handlungsempfehlungen und der Identifikation vorhandener Forschungslücken. Die vorgestellten Forschungsarbeiten implementieren überwiegend Simulations- und Optimierungsverfahren unter besonderer Betrachtung von relevanten Einflussfaktoren in der Lebensmittelbranche wie Kühlkettenmanagement und geringen Haltbarkeiten. Ein Schwerpunkt liegt hierbei auf der Integration von Modellen zur Berechnung der Resthaltbarkeit von Produkten um Qualität in Echtzeit überprüfen und Planungsentscheidungen dynamisch anpassen zu können. Für weitere Forschungstätigkeiten sind eine genauere Betrachtung der Anforderungen von EndkundInnen sowie ein stärkerer Fokus auf holistische Lösungen empfehlenswert.

Schlagworte: Lebensmittellogistik, Entscheidungsunterstützung, Haltbarkeit, Simulation, Optimierung 


\section{Introduction}

Decision support systems (DSSs), that is, "computer technology solutions that can be used to support complex decision making and problem solving" (Shim et al., 2002), provide various benefits to decision makers in the food industry, particularly if time-critical and complex managerial problems are faced. The focus of this work is on reviewing DSSs for last-mile food logistics operations of fresh fruits and vegetables (FFVs), that is, the shipment of such products from distribution centers to either retail stores or customers' premises. FFVs are mainly subject to short shelf lives and, consequently, require special attention to facilitate efficient logistics operations (Fredriksson and Liljestrand, 2015; Soto-Silva et al., 2015).

The first concepts of DSSs were developed in the 1960s and early 1970s, supported by advances in personal computers, database management systems and user-friendly interfaces (Ford, 1985). In contrast to related fields such as expert systems that facilitate various artificial intelligence techniques (Wagner, 2017), DSSs focus on providing the users flexible and personal ways to support decision making processes by assisting in the manipulation of data and underlying models (Ford, 1985). Such systems can be developed for all levels of decision making by combining data access and retrieval features with models and analytic techniques (Sprague, 1980). Within literature, various classifications for related research exists. In this context, Power (2002) classifies DSSs based on the dominant system component, the considered user groups, their general purpose and the enabling technology. Five main types of DSSs, namely communications-driven, data-driven, document-driven, knowledge-driven and model-driven, are listed. Communications-driven ones focus on facilitating communication by providing users tools to collaborate, while data-driven and document-driven ones assist in the retrieval of either data or documents from databases or webpages, respectively. Knowledge-driven DSSs suggest actions to managers based on defined business rules and knowledge bases, while model-driven mainly employ mathematical and statistical methods to support such decisions.

Out of these types, this paper primarily investigates modeldriven ones. Such systems provide decision makers ways to investigate the impact of varying parameters in differing problem settings with quantitative models being the main components. Therefore, particularly in a logistics context, optimization and simulation models are often integrated to model complex systems and consider specific decision makers' objectives (Power and Sharda, 2007). This enables one to investigate various strategies in a fast and risk-free manner and, furthermore, provides an effective way to improve the quality and velocity of decision making by facilitating understanding of the underlying systems.

To enhance research on DSSs, Arnott and Pervan (2008) propose conducting more work based on specific case studies. This is supported by this work, which highlights research on model-driven DSSs in fresh food logistics operations. Demand for such logistics services is currently experiencing high growth rates, while related activities are challenged by vast amounts of complexity and uncertainties present in daily operations. Additionally, transport routes and related infrastructure play a key role to facilitate sustainable land use (Minixhofer et al., 2019). Consequently, detailed research focusing on fast and scalable DSSs to support efficient operations is required to guarantee service quality and mitigate negative impacts on society, health and the environment in the future. The remainder of this paper, which is based on and contains parts of the unpublished Habilitation thesis presented in Fikar (2018), is structured as follows: Section 2 provides an overview of related work. A conceptual model of a DSS and selected computational experiments are presented in Section 3. Section 4 discusses derived implications and identified gaps in literature. Concluding remarks are given in Section 5.

\section{Literature Review}

FFVs, for example, berries and tomatoes, are perishable food products that are mostly characterized by short shelf lives and varying product qualities along the food supply chain. Shelf life is commonly defined as the period during which a product maintains its desired quality attributes (Nunes et al., 2014). For FFVs, quality attributes are mostly based on visual appearance, for example, freshness, color and absence of decay or physiological changes, as well as on texture, for example, firmness, juiciness and crispness (Ayala-Zavala et al., 2004) and on the growers', retailers' and consumers' perceptions (Nunes et al., 2014). Independent of the individual perspective, shelf lives of FFVs are highly dynamic variables affected by specific storage temperatures and transport conditions (Jedermann et al., 2014). If the storage temperature is too low, chilling or freezing damage occurs, while a too high temperature shortens shelf life due to an increased respiration 
rate, which leads to a depletion of nutrient reserves and accelerated fruit deterioration (Nunes et al., 2014). Consequently, efficient logistics operations to ship products swiftly are crucial. Food logistics, however, is highly complex due to challenges related to regulations, food safety and cold chain management (Fredriksson and Liljestrand, 2015). Additionally, compared to non-perishable products, the logistics of perishables is subject to many uncertainties due to varying seasonable supply and demand as well as unpredictable weather conditions influencing harvest times, quality and quantity (Soto-Silva et al., 2015). Within literature, model-driven DSSs for FFVs often focus on impacts of explicitly considering food quality data within logistics operations. Product quality is impacted by the specific cooling system used (James et al., 2006) and further by various logistics decisions made along the food supply chain (Jedermann et al., 2014). The latter includes inventory strategies, the selection of logistics providers, mode of transport choices as well as the number of transshipment points and hubs used. At each such point, products may be exposed to delays and temperature changes affecting product quality. Within this context, recent operations research applications for FFVs supply chains are reviewed in Soto-Silva et al. (2015). Multiple articles using simulation and optimization methods are introduced, however, the review article concludes that more work in the field is required that considers uncertainty and investigates its impact on FFVs supply chains. In van der Vorst (2009), integrated decision making in a food supply chain is investigated with the aim to improve transparency in food supply chains. A discrete-event simulation is developed considering multiple food quality models for a range of fresh products. Both food quality and cost factors are further integrated within the modeling of FFVs supply chain processes in Rong et al. (2011). A mixedinteger programming (MIP) model is developed considering quality degradation as a linear function of temperature and storage durations to show the potential of integrating food quality models within fresh food DSSs. Bortolini et al. (2016) consider a multi-objective problem setting for tactical distribution network planning of FFVs. Within this study, food quality is dependent on the delivery time. The developed linear programming model is tested on a case study of Italian producers with results highlighting benefits of jointly considering costs, food quality and emissions. The impact of including climate data in the distribution planning of FFVs is studied in Accorsi et al. (2017) through the development of an MIP. That authors show that integrating such data enables one to reduce energy consumption during transportation and storage. Leithner and Fikar (2019) investigate an organic strawberry supply chain with the aim to identify benefits of facilitating quality data throughout logistics operations. Therefore, the authors assume various stock rotation schemes and further consider different priorities of end consumers concerning desired product quality. Results show the high impact the selected distribution strategy has on sales and food waste. In addition, various authors focus on considering food quality within vehicle routing problems (VRPs), which deal with the planning of delivery routes (Braekers et al., 2016). Tarantilis and Kiranoudis (2001) introduce a metaheuristic to optimize the distribution of perishable food. The problem is modeled as a Heterogeneous Fixed Fleet VRP and is tested on a real-world milk distribution setting with the objective to reduce travel distances. Shelf life of products based on storage temperatures are not explicitly considered. Energy, inventory and transportation costs are jointly optimized in Hsu et al. (2007) for the distribution of lunch boxes. Quality losses are incorporated through a random variable and impacted by the times the vehicles' doors are opened. A bi-objective problem setting is considered in Amorim and Almada-Lobo (2014). The authors study trade-offs between minimizing routing costs and maximizing the average freshness of requests at delivery. Results highlight the impact delivery time windows are having on operations. In Mirzaei and Seifi (2015), a mathematical model for inventory routing problems for perishable goods is presented. The authors assume that demand for products decreases exponentially based on age. Lost sales, inventory and transportation costs are minimized by a metaheuristic solution procedure based on Tabu Search and Simulated Annealing. Song and Ko (2016) integrate various factors influencing food quality within a VRP for a local food retailer performing home deliveries. Both refrigerated and ambient products are considered. Customer satisfaction is influenced by the number of times storage doors are opened before delivery for various vehicle types. To solve the corresponding optimization problem, a nonlinear mathematical formulation and a priority-based heuristic are developed. Fikar et al. (2018) focus on restaurant deliveries. A simulation and optimization-based DSS is introduced, which considers both freelancers and the option to fulfill orders from multiple restaurant locations. To consider food quality, minimizing delivery times is of focus. With a focus on FFVs, Hsiao et al. (2018) model food quality during last-mile distribution based on changing temperature. Strawberries and lima beans are taken as sample products with product value 
being categorized into five classes based on remaining shelf lives. A modified genetic algorithm is developed to optimize routing decisions with the objective to minimize total costs. Estrada-Moreno et al. (2019) aim to reduce food waste by repositioning perishable inventory between multiple store locations. A metaheuristic solution procedure is developed and food quality is considered through the introduction of delivery deadlines and penalties.

Focusing on e-grocery operations, that is, the purchase of food items online, Fikar (2018) introduces a model-driven DSS to investigate food quality losses during last-mile delivery operations. Various picking strategies and routing objectives are considered to investigate impacts on driving distances, food waste and delivered food quality. Computational experiments show major trade-offs within daily operations and highlight the importance to investigate such factors in detail. This work is extended in Fikar et al. (2019) by integrating consumer preferences. Based on a survey and conjoint analysis of over 400 consumers in Vienna, Austria, the authors estimate part-worth utilities for various features of an e-grocery service offer such as the remaining shelf life of the delivered products, the delivery fee and offered time windows. Results are integrated in a DSS, which simulates demand and optimizes delivery routes throughout multiple weeks of operations.

The reviewed literature is summarized in Table 1, listing the focus areas, primary methods used and which kind of uncertainty was considered in these articles. To support decision making, various model-driven DSSs either focus on optimization or simulation methods. Food quality is further modelled in multiple ways, either by introducing random product quality, varying yield or by the consideration of time and temperature effects.

\section{Model-driven DSS for fresh food logistics operations}

Figure 1 links key components found in literature within a single model-driven DSS. At the center stands the user of the system who is influenced by regulations, product characteristics, forecasts and the respective company strategy. He or she defines the problem setting, inputs data and varies parameters of interest. Important data sources include the shipped products, relevant locations such as warehouses and stores, available vehicles for deliveries as well as information about customers and the transport network. This data acts as an input to the simulation model, which generates demand and simulates operations. At certain times during the planning horizon, it communicates with food quality models and optimization procedures to perform order picking decisions, plan delivery routes or replenish inventory. The consideration of product quality as a dynamic factor subject to storage temperature and travel duration is a

Table 1. Overview of reviewed literature

Tabelle 1. Übersicht der analysierten Literatur

\begin{tabular}{llll}
\hline & Focus Area & Primary Method & Considered Uncertainty \\
\hline Tarantilis and Kiranoudis (2001) & Distribution planning & Metaheuristic & - \\
Hsu et al. (2007) & Last-mile deliveries & Metaheuristic & Travel speed \\
van der Vorst (2009) & Supply chain redesign & Simulation & Product Quality; Yield \\
Rong et al. (2011) & Distribution planning & Exact optimization & - \\
Amorim and Almada-Lobo (2014) & Distribution planning & Metaheuristic & - \\
Mirzaei and Seifi (2015) & Distribution planning & Exact optimization & - \\
Bortolini et al. (2016) & Network planning & Exact optimization & - \\
Song and Ko (2016) & Distribution planning & Exact optimization & - \\
Accorsi et al. (2017) & Distribution planning & Exact optimization & - \\
Fikar (2018) & Last-mile deliveries & Simulation & Product quality; demand \\
Fikar et al. (2018) & Last-mile deliveries & Simulation & Demand \\
Hsiao et al. (2018) & Last-mile deliveries & Metaheuristic & - \\
Estrada-Moreno et al. (2019) & Last-mile deliveries & Metaheuristic & - \\
Fikar et al. (2019) & Last-mile deliveries & Simulation & Demand; Preferences \\
Leithner and Fikar (2019) & Distribution planning & Simulation & Quality; Yield; Demand \\
\hline
\end{tabular}




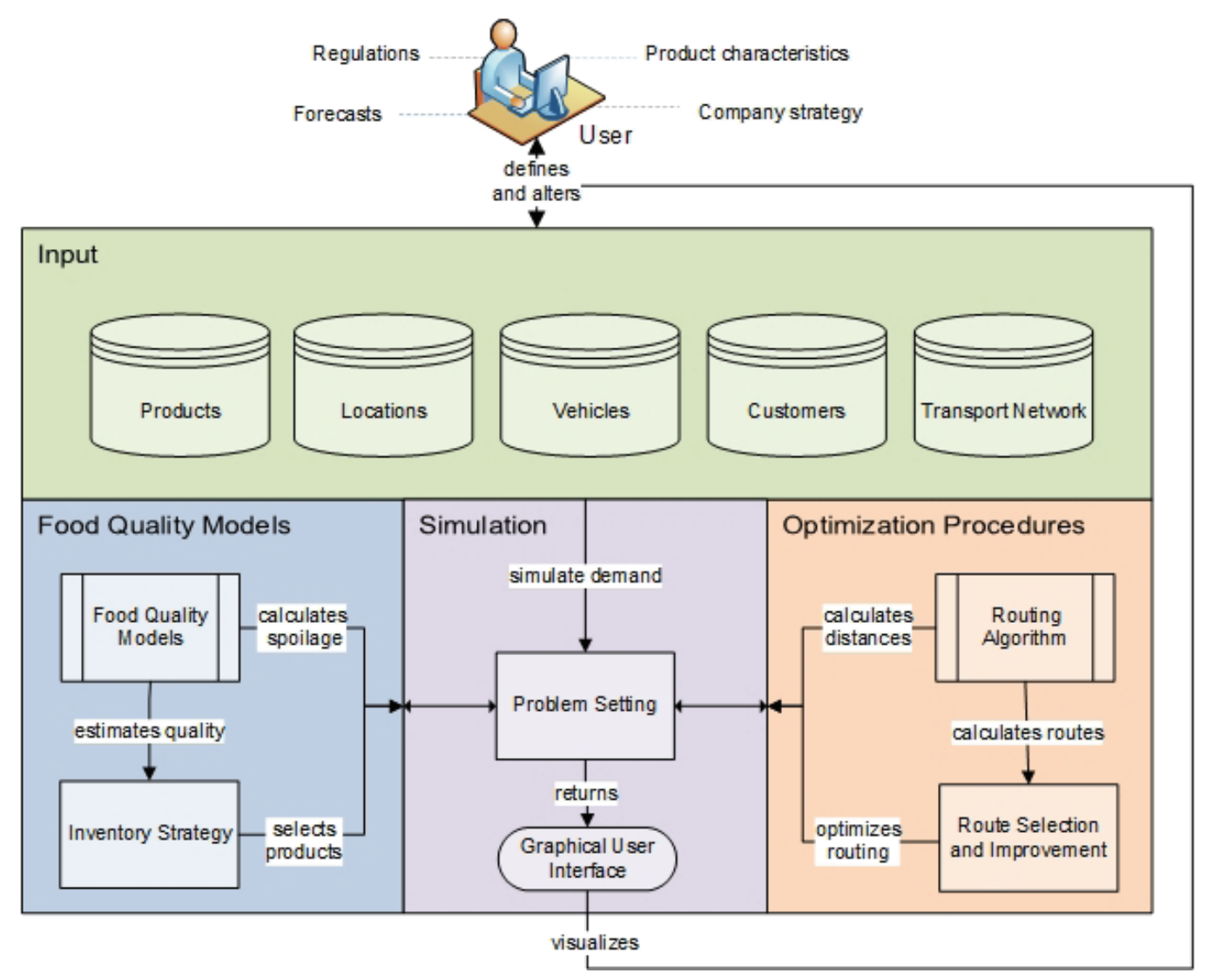

Figure 1. A concept of a model-driven DSS for fresh food logistics linking key components found in literature Abbildung 1. Konzept eines modellgetriebenen Entscheidungsunterstützungssystems für die Zustellung frischer Lebensmittel inklusive identifizierter Schlüsselkomponenten

key feature in related work. Such temperature changes are mostly calculated through the integration of food quality models with the majority of considered model-driven DSSs employing the method introduced in Tijskens and Polderdijk (1996). Optimization models are further developed to plan vehicle tours through exact methods or metaheuristic solution procedures. Common objectives in this context are to reduce travel distances, costs, emissions or to focus on food waste reduction. To present such results, performance indicators are visualized by a graphical user interface within the DSS. This motivates the user to test varying strategies to derive decisions in a flexible manner. Additionally, it facilitates improved problem understandings and highlights independencies present in daily food logistics operations.

To highlight benefits of such a joint implementation, a sample setting derived from e-grocery deliveries in Vienna, Austria, is considered. The DSS, which is based on Fikar (2018), was developed in the simulation software AnyLogic 8.5.1 with the optimization procedure and integrated food quality model coded in Java. A single day of operations is simulated and which FFVs have to be matched with orders and delivery tours generated. A central warehouse in the south of Vienna is used to supply customers, which are clustered throughout the city based on electoral districts. The delivery time window is set to three hours and 48 different food products are included. To perform deliveries, ten vehicles are available starting and ending their day at the central warehouse. Daily demand is varied within the experiments between 500 and 1,000 FFVs. Temperature along storage and delivery processes are set to $277.15 \mathrm{~K}$, that is, $4{ }^{\circ} \mathrm{C}$. All other parameters are set in accordance with Fikar (2018). For further reference, the complete input data is available at https://short.boku.ac.at/instances. Table 2 provides the average number of shipped items, resulting food waste and the average delivered food quality within the computational experiments. A mean \pm SD notation is used with each value representing 100 simulation replications. The optimization objective is set to minimize total travel distances. To investigate benefits of considering food quality models and optimization procedures within 
Table 2. Results of the computational experiments

Tabelle 2. Ergebnisse der Computerexperimente

\begin{tabular}{llll}
\hline & & \multicolumn{2}{c}{ Expected demand: 500 items per day } \\
\hline & Items Shipped (units) & Food Waste (units) & Food Quality (days) \\
FEFO & $494.44 \pm 4.24$ & $14.08 \pm 3.58$ & $3.57 \pm 0.67$ \\
LEFO & $492.06 \pm 4.93$ & $54.40 \pm 6.51$ & $6.33 \pm 0.43$ \\
Random & $494.01 \pm 5.30$ & $34.62 \pm 5.29$ & $4.98 \pm 0.53$ \\
\hline & & Expected demand: 750 items per day & Food Quality (days) \\
\hline & Items Shipped (units) & Food Waste (units) & $3.71 \pm 0.46$ \\
FEFO & $740.19 \pm 8.89$ & $17.52 \pm 4.21$ & $6.23 \pm 0.30$ \\
LEFO & $736.75 \pm 9.16$ & $75.26 \pm 7.55$ & $5.00 \pm 0.38$ \\
Random & $739.30 \pm 7.48$ & $44.86 \pm 6.37$ & Food Quality (days) \\
\hline & & Food Waste (units) & $3.79 \pm 0.41$ \\
FEFO & Items Shipped (units) & $21.40 \pm 4.82$ & $6.07 \pm 0.25$ \\
LEFO & $985.18 \pm 13.46$ & $95.53 \pm 9.86$ & $4.95 \pm 0.32$ \\
\hline
\end{tabular}

related model-driven DSSs, three varying settings are compared. First-expired first-out (FEFO) focuses on reducing food waste by shipping products with short shelf lives first to customers. In contrast, last-expired first-out (LEFO) favors ones with long remaining shelf lives. These two settings are compared with a random product selection, that is, the setting where no food quality data is facilitated in the DSS. As the results highlight, providing such an option to match products with orders according to their remaining shelf lives leads to various benefits. Depending on the main objective of the decision maker, it allows one to either substantially reduce food waste or increase the delivered food quality.

\section{Discussion}

Based on the literature review and performed computational experiments, the following subsections discuss derived implications and identified research gaps.

\subsection{Implications}

The implementation of simulation and optimization-based DSSs within food logistics operations enables one to derive various implications of interest. Key findings include the importance of considering uncertainty in both supply and demand as well as benefits of integrating food quality and customer data in logistics planning processes.

\subsubsection{Consideration of uncertainties present in daily logistics operations}

Food logistics operations are subject to various uncertainties such as uncertain supply, uncertain demand and varying food quality (Soto-Silva et al., 2015). Such factors can substantially challenge logistics operations, and, consequently, need to be considered closely within the development of related DSSs. Results of performed computational experiments further highlight large trade-offs between minimizing travel distances and reducing food quality losses during last-mile distribution (Amorim and Almada-Lobo, 2014; Fikar, 2018). Additionally, interdependencies between offered services and logistics performance are important to consider jointly. For instance, if one aims to offer higher food quality to customers, it has large implications on inventory levels and requires additional delivery vehicles to reach customer on time (Fikar et al., 2019). Simulation and optimization methods enable one to model such factors to derive implications and support sustainable operations.

\subsubsection{Integrating food specifics within logistics DSSs}

Particularly within last-mile distribution of fresh food, a wide range of handling and storage requirements need to be closely considered to deliver products in the right quality, on-time and at low costs. Products often share common characteristics such as optimal temperature ranges, however, differ substantially based on the specific use 
case. The quality of lunch boxes is mainly influenced by transport durations and door openings (Hsu et al., 2007), while for restaurant deliveries, delivery speed and pickup locations are of particular importance (Fikar et al., 2018). Consequently, tailored decision support, which integrates industry-specifics and enables one to consider varying business models, need to be provided to support successful implementations in the future.

\subsection{Research Gaps}

Various research directions of interest originate from this work. The following part introduces selected topics of importance.

\subsubsection{Integration of behavioral factors}

To improve understanding and support real-world implementations of DSSs, more work on behavioral questions is required (Power and Sharda, 2007). Within food logistics, the consideration of customer preferences is a first step in this direction and first results highlight its benefits. For instance, achieved customer utility highly depends on individual perceptions and, consequently, product selection is a crucial step within e-grocery operations (Fikar et al., 2019). By facilitating various data sources such as loyalty cards and social media activities, logistics processes can be pro-actively adjusted to improve service quality. Substantial future work, however, is required to improve understanding and support a better representation of actions and interactions between agents and the environment within fresh food supply chains. Examples include impacts of word-of-mouth, delays and supply shortages. Additionally, as demand for FFVs is growing significantly due to changes in diets (Reynolds et al., 2014), incorporating such changes and their consequences on related delivery processes is of interest. By having such knowledge available and integrating it in model-driven DSSs, an improvement in service quality as well as a reduction in logistics costs and food waste can be achieved.

\subsubsection{Cost and risk-sharing mechanisms to mitigate disruptions}

A further point of interest is the development of supply chain coordination mechanisms specific to fresh food delivery operations, for example, through cost and risk-sharing agreements. For instance, prioritizing inventories close to expiration enables one to reduce cost and food waste in the system (Jedermann et al., 2014). Furthermore, it allows one to develop quality thresholds to decide at which point products should be shifted to alternative distribution channels (Leithner and Fikar, 2019). Additional costs of such activities need to be compensated in order to achieve fair and robust operations. This is particularly crucial in horizontal coordination agreements to build trust and achieve stable conditions (Serrano-Hernandez et al., 2018). The development of new methods to achieve better coordination within fresh food supply chains facilitates both evaluations and implementations of such mechanisms.

\subsubsection{Consideration of interdependencies and holistic approaches}

Fresh food logistics operations are highly complex and, consequently, require holistic approaches to consider the specifics of shipped products and related customer expectations. For instance, multiple papers stress the importance of considering door openings (Hsu et al., 2007; Song and Ko, 2016) in logistics planning procedures as resulting heat and mass transfers can negatively impact food quality (James et al., 2006). More recently, a stronger focus is further set on ethylene production and its impact on spoilage rates (Yang et al., 2019) as well as on delivery vehicles with multiple temperature zones (Martins et al., 2019). As the presented concept of a model-driven DSS in Figure 1 highlights, decisions regarding offered services, inventory policies and distribution strategies are closely interconnected within fresh food operations. Consequently, related factors need to be considered jointly to enable one to reduce costs, emissions and food waste. Model-driven DSS allow such considerations, implementations, however, are not trivial as more work to understand interdependencies present in food logistics and their impact on operations is required.

\section{Conclusions}

As demand for FFVs is growing significantly, tailored and scalable solutions are required to facilitate successful logistics operations in the future. This work highlighted recent work on model-driven DSSs with a focus on last-mile distribution of FFVs. Most articles develop simulation and optimization methods considering various uncertainties present in daily operations such as dynamic product qualities and variations in supply, demand and consumer behaviors. Therefore, food quality models are often integrated. Furthermore, a special focus is set on VRPs and the reduction of food waste and quality losses. Findings highlight that model-driven DSSs 
can assist efficient and sustainable operations, provide decision support on how to set up corresponding systems and further support the professional development of decision makers by highlighting emerging topics and facilitating improved understanding of key influencing factors. Nevertheless, future work is required to increase the relevance of related research. Topics of interest are a stronger integration of behavioral factors, supply chain risk management and coordination strategies as well as holistic approaches to gain a broader understanding of fresh food supply chains.

\section{Acknowledgements}

Financial support by the WU Jubiläumsstiftung through the project 'Incorporating food quality in e-grocery logistics optimization' is gratefully acknowledged.

\section{References}

Accorsi, R., Gallo, A. and R. Manzini (2017): A climate driven decision-support model for the distribution of perishable products. Journal of Cleaner Production, 165, 917-929.

Amorim, P. and B. Almada-Lobo (2014): The impact of food perishability issues in the vehicle routing problem. Computers \& Industrial Engineering 67, 223-233.

Arnott, D. and G. Pervan (2008): Eight key issues for the decision support systems discipline. Decision Support Systems 44, 657-672.

Ayala-Zavala, J., Wang, S.Y., Wang, C.Y. and G.A. González-Aguilar (2004): Effect of storage temperatures on antioxidant capacity and aroma compounds in strawberry fruit. LWT - Food Science and Technology 37, 687-695.

Bortolini, M., Faccio, M., Ferrari, E., Gamberi, M. and F. Pilati (2016): Fresh food sustainable distribution: cost, delivery time and carbon footprint three-objective optimization. Journal of Food Engineering, 174, 56-67.

Braekers, K., Ramaekers, K. and I. Van Nieuwenhuyse (2016): The vehicle routing problem: State of the art classification and review. Computers \& Industrial Engineering 99, 300-313.

Estrada-Moreno, A., Fikar, C., Juan, A. and P. Hirsch (2019): A biased-randomized algorithm for redistribution of perishable food inventories in supermar- ket chains. International Transactions in Operational Research 26, 2077-2095.

Fikar, C. (2018): A decision support system to investigate food losses in e-grocery deliveries. Computers \& Industrial Engineering 117, 282-290.

Fikar (2018): Decision Support for Time-Critical Logistics Operations. Habilitation Thesis, University of Natural Resources and Life Sciences Vienna (BOKU), Vienna, pp. 294.

Fikar, C., Hirsch, P. and M. Gronalt (2018): A decision support system to investigate dynamic last-mile distribution facilitating cargo-bikes. International Journal of Logistics: Research and Applications 21, 300-317.

Fikar, C., Mild, A. and M. Waitz (2019): Facilitating consumer preferences and product shelf life data in the design of e-grocery deliveries. European Journal of Operational Research, in press. doi: 10.1016/j. ejor.2019.09.039

Ford, F.N. (1985): Decision support systems and expert systems: A comparison. Information \& Management 8, 21-26.

Fredriksson, A. and K. Liljestrand (2015): Capturing food logistics: a literature review and research agenda. International Journal of Logistics Research and Applications $18,16-34$.

Hsiao, Y.H., Chen, M.C., Lu, K.Y. and C.L. Chin (2018): Last-mile distribution planning for fruit-and-vegetable cold chains. The International Journal of Logistics Management 29, 862-886.

Hsu, C.-I., Hung, S.-F. and H.-C. Li (2007): Vehicle routing problem with time-windows for perishable food delivery. Journal of Food Engineering 80, 465-475.

James, S.J., James, C. and J.A. Evans (2006) Modelling of food transportation systems - a review. International Journal of Refrigeration 29, 947-957.

Jedermann, R., Nicometo, M., Uysal, I. and W. Lang (2014): Reducing food losses by intelligent food logistics. Philosophical Transactions of the Royal Society A: Mathematical, Physical and Engineering Sciences 372, 20130302.

Leithner, M. and C. Fikar (2019): A simulation model to investigate impacts of facilitating quality data within organic fresh food supply chains. Annals of Operations Research, in press. doi:10.1007/s10479-019-03455-0

Martins, S., Ostermeier, M., Amorim, P., Hübner, A. and B. Almada-Lobo (2019): Product-oriented time window assignment for a multi-compartment vehicle rout- 
ing problem. European Journal of Operational Research 276, 893-909.

Minixhofer, P., Stangl, R., Baumgarten, A., Huber, S., Weigl, M., Tramberend, P. and S. Zechmeister-Boltenstern (2019): INSPIRATION for Sustainable Soil and Land Use Management in Austria. Die Bodenkultur: Journal of Land Management, Food and Environment 70, 113-123.

Mirzaei, S. and A. Seifi (2015): Considering lost sale in inventory routing problems for perishable goods. Computers and Industrial Engineering 87, 213-227.

Nunes, M.C.N., Nicometo, M., Emond, J.P., Melis, R.B. and I. Uysal (2014): Improvement in fresh fruit and vegetable logistics quality: berry logistics field studies. Philosophical Transactions of the Royal Society A: Mathematical, Physical and Engineering Sciences 372 20130307-20130307.

Power, D. (2002): Decision Support Systems: Concepts and Resources for Managers. Quorum Books, Westport, CT, USA, pp. 284.

Power, D.J. and R. Sharda (2007): Model-driven decision support systems: Concepts and research directions. Decision Support Systems 43, 1044-1061.

Reynolds, C.J., Buckley, J.D., Weinstein, P. and J. Boland (2014): Are the dietary guidelines for meat, fat, fruit and vegetable consumption appropriate for environmental sustainability? A review of the literature. Nutrients 6, 2251-2265.

Rong, A., Akkerman, R. and M. Grunow (2011): An optimization approach for managing fresh food quality throughout the supply chain. International Journal of Production Economics 131, 421-429.

Serrano-Hernandez, A., Hirsch, P., Faulin, J. and C. Fikar (2018): Agent-based simulation for horizontal cooperation in logistics and transportation: from the individual to the grand coalition. Simulation Modelling Practice and Theory 85, 47-59.
Shim, J., Warkentin, M., Courtney, J.F., Power, D.J., Sharda, R. and C. Carlsson (2002): Past, present, and future of decision support technology. Decision Support Systems 33, 111-126.

Song, B.D. and Y.D. Ko (2016): A vehicle routing problem of both refrigerated and general-type vehicles for perishable food products delivery. Journal of Food Engineering 169, 61-71.

Soto-Silva, W.E., Nadal-Roig, E., González-Araya, M.C. and L.M. Pla-Aragones (2015): Operational research models applied to the fresh fruit supply chain. European Journal of Operational Research 251, 345-355.

Sprague, R.H. (1980): A framework for the development of decision support systems. MIS Quarterly 4, 1-26.

Tarantilis, C. and C. Kiranoudis (2001): A meta-heuristic algorithm for the efficient distribution of perishable foods. Journal of Food Engineering 50, 1-9.

Teller, C., Holweg, C., Reiner, G. and H. Kotzab (2018): Retail store operations and food waste. Journal of Cleaner Production 185, 981-997.

Tijskens, L.M.M. and J.J. Polderdijk (1996): A generic model for keeping quality of vegetable produce during storage and distribution. Agricultural Systems 51, 431-452.

van der Vorst, J., Tromp, S.-O. and D.-J. van der Zee (2009): Simulation modelling for food supply chain redesign; integrated decision making on product quality, sustainability and logistics. International Journal of Production Research 47, 6611-6631.

Wagner, W.P. (2017): Trends in expert system development: A longitudinal content analysis of over thirty years of expert system case studies. Expert Systems with Applications 76, 85-96.

Yang, Y., Chi, H., Tang, O., Zhou, W. and T. Fan (2019): Cross perishable effect on optimal inventory preservation control. European Journal of Operational Research 276, 998-1012. 